\title{
HACIA UNA NUEVA MONUMENTALIDAD: REVISIÓN MODERNA DE SU SIMBOLISMO ARQUITECTÓNICO (1900-1960) ${ }^{1}$
}

\author{
Emilio Cachorro Fernández \\ Universidad de Granada
}

Data recepción: 2017/01/27

Data aceptación: 2018/01/31

Contacto autor: ecachorro@ugr.es

ORCID: https://orcid.org/0000-0002-7314-9928

\section{RESUMEN}

Las nuevas tesis acerca de la noción de monumentalismo espolearon una de las polémicas más enconadas de la primera mitad del siglo XX, situándose en las raíces genuinas del Movimiento Moderno. La retórica arquitectónica ochocentista, inductora de una gratuita seudomonumentalidad, fue enérgicamente combatida desde múltiples frentes durante varias décadas, tras las que comenzaría a surgir lo que se conoce como "nueva monumentalidad", por cuenta incluso de algunos de los más legítimos exponentes racionalistas. Una larga y heterogénea sucesión de criterios que ha motivado un complejo relato historiográfico, instando a profundizar en los argumentos más influyentes de los grandes maestros modernos sobre esta materia, por etapas evolutivas desde el vanguardismo hasta la transición a la contemporaneidad, algunos escasamente considerados hasta la fecha, lo que permitirá completar la secuencia de previa crisis y posterior recuperación del monumento, mediante un brusco viraje ideológico, como hecho sociocultural irrenunciable pero expresado con el nuevo lenguaje de la época sin clichés preestablecidos.

Palabras clave: monumento, nueva monumentalidad, arquitectura moderna, imagen urbana

\section{ABSTRACT}

The new thesis on the concept of monumentalism spurred one of the most bitter debates of the first half of the 20th century, impacting on the true roots of modern architecture. Nineteenth-century architectural rhetoric, which prompted a gratuitous pseudo-monumentality, was vigorously resisted on a number of fronts for several decades, at which point what is known as "a new monumentality" began to emerge, proposed in some cases by even the most legitimate exponents of rationalism. This long and diverse succession of criteria has resulted in a complex historiographical account, which has triggered detailed analyses of the most influential arguments posited by the great modern masters on this subject, through evolutionary stages from the avant-garde to the transition to contemporaneity, some of which have barely been given any consideration to date. Such consideration would enable completion of the sequence of the initial crisis and subsequent recovery of the monument, achieved by means of a radical ideological shift, as a sociocultural fact that is undeniable but expressed with the new language of the time and without time-honoured clichés.

Keywords: monument, new monumentality, modern architecture, urban image 


\section{1900-1925: insumisión vanguardista}

A lo largo de la historia siempre se ha recurrido a la idea de monumento como construcción resorte para evocar, de manera emotiva, toda suerte de eventos, rituales o creencias, contribuyendo a preservar la memoria frente a la acción abrasiva del tiempo y la condición efímera de su fundador. Esta facultad semiótica se desarrolla básicamente a través de corrientes estilísticas que definen rasgos tipológicos y elementos ornamentales, cuyo particular léxico es reconsiderado y, en su caso, reinterpretado durante cada período. Todo ello sin excepción de cultura y época, pero con un importante declive desde la megalómana etapa napoleónica, a partir de la que desplegaría una gran banalidad con independencia de regímenes políticos. La retórica del eclecticismo decimonónico fue causando una pérdida generalizada del respeto a la tradición, empleando modelos pasados de modo cada vez más indiscriminado, falso y decorativo, sin fundamentarse en otro criterio que no fuera la sumisión al gusto dominante, para satisfacer bajos instintos, lo que terminó degenerando en una seudomonumentalidad ${ }^{2}$.

Heredera de estos espurios precedentes, la modernidad tendría que asumir la responsabilidad de volver a plantearse, con férrea determinación, cuál debía ser el papel que entraña un concepto tan decisivo en arquitectura, así como la forma de hacerse plenamente efectivo. De esta manera comenzaron a fijarse algunos relevantes posicionamientos, aunque todavía de carácter aislado. Uno de los primeros fue por cuenta de Aloïs Riegl, tras su nombramiento como presidente de la comisión austríaca de monumentos históricos, a quien se le encomendó redactar un plan de conservación a partir del cambio de mentalidad suscitado por la nueva época, cuyas argumentaciones teóricas fueron compiladas en Der moderne denkmalkultus (El culto moderno a los monumentos) ${ }^{3}$ en 1903, donde distingue varias clases interrelacionadas de «valores conmemorativos», que amplían el número de bienes catalogables debido a la mayor cantidad de cualidades reconocidas, por este orden: en su sentido más primigenio, el 'valor recordatorio intencionado', esencialmente patriótico, propio de las culturas clásica y medieval; contrapuesto a la consideración de 'valor histórico', no previsible de origen, que fue calando del siglo XVI al XIX; y el 'valor de antigüedad', admitido más recientemente, consecuencia del paso del tiempo pero sin formar parte de un relato cronológico. A lo que hay que añadir los "valores contemporáneos" que derivan de la capacidad de satisfacer necesidades materiales y espirituales del hombre, como lo hacen las edificaciones actuales, entre los que cabe señalar: el 'valor instrumental', dado por su finalidad práctica; y el 'valor artístico', en el que hay que diferenciar el 'valor de novedad', que concierne a un aspecto fresco e intacto de la obra que supuestamente la dota de mayor hermosura, y el 'valor artístico relativo', basado en una notoria coincidencia con la sensibilidad estética del momento.

Unas reflexiones que alentaron el debate sobre la monumentalidad justo cuando la arquitectura se encontraba en un crítico punto muerto, postrada a un fachadismo carente de rasgos expresivos de su época, tan solo plasmados en las construcciones mecanicistas, desnudas pero sinceras, que se postulaban como sustento de un nuevo lenguaje surgido de las energías del mundo moderno. La progresiva tirantez generada en la relación entre esencia y apariencia solo era posible resolverla de dos modos totalmente contrapuestos: bien se recuperaba el emparejamiento entre artesanía y arte, a través de una fórmula que conciliara razón y espíritu, según promulgaron colectivos afines al movimiento Arts and Crafts, incluidos los valedores de procesos industriales como el Deutscher Werkbund y la Bauhaus, cuyos miembros abogaban por la gesamtkunstwerk ${ }^{4} \mathrm{u}$ «obra de arte total»; o bien se aceptaba que son dos aspectos independientes, en consonancia con las reputadas teorías de profesionales como Adolf Loos. Según éste, a través de lo expuesto en su Architektur en 1910 -escrito también surgido en el ámbito vienés-5, las viviendas tienen que adecuarse al gusto colectivo en su exterior, y no solo a los del propietario y el arquitecto, dado el carácter funcional con el que nacen, de trascendencia pública, lo que exige moderar cualquier tipo de planteamiento. Por el contrario, la producción artística se debe de manera exclusiva a la voluntad de su autor, constituye algo privado, no concebido con un propósito meramente estético sino para remover los más hondos sentimientos, donde innovación y provocación son muy bienve- 
nidas. Con estos razonamientos, se preguntaba si se debía incluir su disciplina entre las artes, lo que niega rotundamente salvo en los casos de monumentos funerarios y monumentos conmemorativos; todo lo demás debe quedar excluido puesto que sirve a un fin determinado, aspecto que resulta incompatible con el reino plástico, por lo que se debía abolir el dañino ornamento aplicado.

De otra parte, en la primavera de 1911, precisamente animado por los preceptos de la Werkbund alemana, Walter Gropius pronunciaría su conferencia sobre Monumentale kunst und industriebau (Arte monumental y construcción industrial) ${ }^{6}$ en el Folkwang museum de Hagen, seguida dos años más tarde de su crucial ensayo Die entwicklung moderner industriebaukunst (La evolución de las técnicas de construcción industrial moderna)', donde puso como ejemplo algunas obras proyectadas por Hans Poelzig y, principalmente, por su maestro Peter Behrens, quien acababa de construir parte de las instalaciones de la empresa AEG en Berlín - incluida su sala de montaje de turbinas (1908-1909) -, calificándolas como "denkmäler von adel und kraft" (monumentos nobles y fuertes), cuya concepción simplemente atendía a los principios esenciales de la arquitectura, llegando a dominar el entorno mediante la reinterpretación de una grandeza clásica con la que volvían a emanar profundas emociones, representativa del zeitgeist o "voluntad de su época». Asimismo, su discurso centró la atención en las novedosas tipologías ingenieriles, especialmente norteamericanas, entre las que destacaban unos impactantes silos, que fueron elevadas al mismo rango que los monumentos egipcios: "Die getreidesilos von Kanada und Südamerika, die kohlensilos der großen eisenbahnlinien und die modernsten werkhallen der nordamerikanischen industrietrusts halten in ihrer monumentalen gewalt des eindrucks fast einen vergleich mit den bauten des alten Ägyptens aus" ${ }^{\prime \prime}$, lo que se justificaba no solo por el inmenso tamaño de las estructuras sino, sobre todo, por sus formas compactas (fig. 1).

Se trataba de una revolucionaria visión que no tardó en influenciar, entre otros, a Antonio Sant'Elia, quien la incorporó como contenido de su célebre Messaggio o manifiesto de la arquitec-

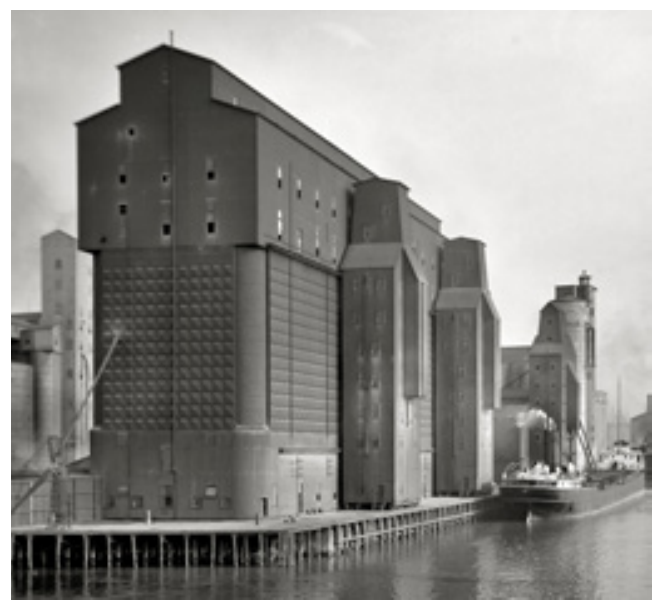

Fig. 1. Dakota elevator, Buffalo (1901, demolido en 1965); imagen de época, similar a la proyectada por Gropius en Monumentale kunst und industriebau en 1911, cuyo manuscrito subraya el potente efecto de su cuerpo central, con estructura metálica, pese al reducido espesor del cerramiento. Fuente: Detroit Publishing Co.

tura futurista en 1914, o a Le Corbusier, de la que hizo vibrante mención en el primer número de L'Esprit Nouveau en $1920^{\circ}$, reeditada posteriormente como capítulo de Vers une architecture en 1923, incorporando muchas de las mismas imágenes manejadas por Gropius. El italiano, junto a su compatriota Filipo T. Marinetti, se haría eco de la sobriedad loosiana pero desde un grado todavía más contundente, proclamando el renovado ideal de belleza, aún embrionario en aquel momento, que se basaba en la pérdida del sentido típico de lo monumental, asociado a lo pesado y estático, para optar por lo ligero, práctico, efímero y veloz, como expresión de un sentimiento ya no atraído hacia catedrales y palacios sino dando preferencia a grandes carreteras, puertos, estaciones y mercados, donde predominaban los alardes técnicos ejecutados mediante hormigón, acero y vidrio, desde una actitud intencionadamente marcada por la austeridad: "Acabemos con la arquitectura monumental fúnebre conmemorativa. Desechemos los monumentos [...]. Yo combato y desprecio: 1) Toda la seudoarquitectura [...]. 2) Toda la arquitectura clásica, solemne, hierática, escenográfica, decorativa, monumental..."10.

A la doctrina maquinista, harto prolífica, también contribuiría Jacobus J. Pieter Oud, especialmente por mediación de la revista De Stijl de la que fue cofundador. Como anticipo ya había in- 
dagado en algunos aspectos como el recogido en su artículo Het monumentale stadsbeeld (La imagen monumental de la ciudad)" en 1917, donde se refiere a la arquitectura como arte plástico, definidor del espacio, que encuentra su expresión más general en el paisaje urbano, determinado tanto por el edificio singular como por la conjunción - u oposición recíproca de forma arbitraria - de bloques, con los que se configuran calles y plazas, responsables de la fisonomía de la ciudad, lo que le hizo augurar que la moderna construcción residencial, cada vez más, iría ocupando el puesto de las intervenciones singulares, como ejemplifica la ampliación del sur de Ámsterdam por el también holandés Hendrik Petrus Berlage. A la publicación anterior le seguiría un segundo texto, casi consecutivo e igual de sucinto, titulado Kunst en machine (Arte y máquina) 12, en el que intenta precisar el concepto de monumentalidad, arguyendo: "...monumentaliteit verstaan: georganiseerde en beheerschte verhouding van het subjectieve tot het objectieve..."13, por cuanto creía que la abstracción, entendida como purificación, era el lenguaje que allanaba el camino de lo universal, con el que se posibilitaba la reunión de todas las artes.

Una postura conciliadora sobre la que, pocos meses después, ahondaría su correligionario Theo van Doesburg al escribir Aanteekeningen over monumentale kunst (Notas sobre arte monumental) ${ }^{14}$ en 1918, a raíz de la fructuosa colaboración que sostuvo con Oud en el diseño de la residencia vacacional de verano para jóvenes solteras 'De Vonk' (La Chispa) en Noordwijkerhout (1917-1919), donde introdujo numerosos elementos cromáticos. Su propuesta, también conocida como «arte cooperativo», era una evolución del gemeenschapskunst o «arte comunitario» emprendido igualmente por Berlage unas décadas antes, pero sin connotaciones simbólicas de orden socioreligioso y extensivo a toda clase de edificios - no solo públicos - . El texto empezaba proclamando que la conciencia de la nueva estética bautizada como neoplasticismo requería la unión de todas las artes, con el noble fin de lograr un puro estilo monumental, sobre la base de una relación perfectamente equilibrada o proporcionada, es decir, restringiéndose cada una de ellas a su específico campo de trabajo, como ya se hacía en la antigüedad, lo que se contra- pone al arte decorativo o aplicado; se trataba de garantizar una independencia que preservara la verdadera esencia de cada medio expresivo. De este modo, rechazaba abiertamente los empachosos adornos y relieves barrocos para, en su lugar, reivindicar las superficies planas, los colores lisos y la relación espacial, como recursos propios de la monumentalidad arquitectónica que debía imperar a partir de entonces.

En este contexto, ni tan siquiera pudieron subsistir los Nuevos Tradicionalistas -contrapuestos a los Nuevos Pioneros -, según los denominó Henry-Russell Hitchcock ${ }^{15}$, emergidos durante la primera década del siglo para mantener una línea conservadora mediante la adopción de un lenguaje historicista de trazado libre, sin rígidas ataduras a principios estilísticos, buscando un equilibrio armónico entre pasado y presente a los problemas de los últimos cincuenta años. Ahora bien, todo ello no resultaba óbice para que, arquitectos como el propio Le Corbusier, dejaran entrever una respetuosa consideración hacia los monumentos existentes, especialmente referida a la precisión y perfección clásicas, así como al importante papel que desempeñan en la configuración de la ciudad ${ }^{16}$. Buena prueba es su conocida lección de Roma, donde incluye un dibujo - repetitivo de otro de 1915 - en el que la continuidad urbana queda rota por edificios singulares, con claros componentes histórico y plástico; así como, de otra parte, a pesar de mostrar gran radicalidad, su plan Voisin (1925) evidencia que tuvo en cuenta los edificios más representativos de París, resaltados en algunos croquis como hitos a conservar dentro de la nueva ordenación, característicos del paisaje identificativo de la capital francesa, sin perjuicio de que pasaran a dialogar con modernos rascacielos de vidrio como nuevos integrantes del mismo sistema.

\section{1925-1940: afianzamiento crítico mo- derno}

El segundo cuarto del siglo vería sus comienzos jalonados con múltiples y enardecidas polémicas. Una de las más significativas estalló a partir del concurso internacional para el palacio de la Sociedad de Naciones en Ginebra en 1927, donde resultó vencedor el lenguaje académico a través de una propuesta neoclásica, preferida a otras 


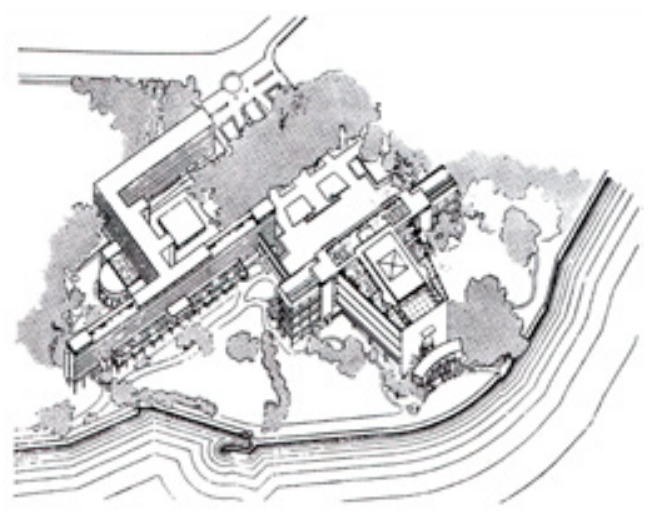

Fig. 2. Le Corbusier y Pierre Jeanneret: proyecto para el palacio de la Sociedad de Naciones, Ginebra (1927-1928); axonometría general, con sus dos edificios de Secretariado y Gran Sala de Asambleas. Fuente: Fondation Le Corbusier

de corte vanguardista como las de Le Corbusier y Pierre Jeanneret (fig. 2), Hannes Meyer y Hans Wittwer, Richard J. Neutra o Erich Mendelsohn. Disputa cuyos ecos no habían dejado de resonar cuando el gran maestro suizo-francés volvió a ser objeto de controversia, esta vez a propósito de su proyecto para el Mundaneum en la misma ciudad (1929), concebido como capital de la cultura mundial en la que se imbuía una monumentalidad tomada de diversas referencias del pasado, el cual fue objeto de duras críticas provenientes de Karel Teige, enérgicamente rebatidas por su autor mediante la exaltación de la estética como un cometido humano trascendental, dado que las personas somos cerebro y corazón, intelecto y pasión, lo que exige proyectar atendiendo tanto a lo funcional como a lo compositivo; de este modo, los aspectos de utilidad, independientes de los relativos a la belleza, deben ser «arquitecturizados», recurriendo a juegos de volúmenes, luz, proporciones, trazados reguladores... ${ }^{17}$.

Un criterio que distanciaba notablemente a los arquitectos modernos más afines al purismo de los encuadrados en la Neue Sachlichkeit alemana, puesto que los primeros defendían que el deseo de afrontar la realidad no alcanza a anular la misión comunicativa de la obra, acusando a la Nueva Objetividad de ser depuradora de academicismos y servidumbres formalistas con raíces beaux-arts pero de una manera severa y coercitiva, mediante un férreo discurso de marchamo represor, enemigo del estatuto libre del traba- jo artístico, debido a que la capacidad creativa requiere un mínimo margen de individualismo para despertar emoción, ajeno a cualquier variable científico-técnica ${ }^{18}$. En cualquier caso, el movimiento moderno había supuesto un serio desafío al estamento oficial, no permitiendo muchos más titubeos en adelante, aunque muchos de sus máximos representantes adoptaran una actitud también positiva frente a lo primitivo y lo autóctono; sirva igualmente el ejemplo de Le Corbusier, haciendo constante alegato en favor de la arquitectura mediterránea de cronología y procedencia diversas, o de Mies van der Rohe, poniendo como referente a las construcciones de madera y las de muros de piedra erigidas en la antigüedad $^{19}$.

Así, desde la opción del ya descrito enfoque antiseparatista de primeros de siglo, el principio de ausencia de decoración aplicada también constituyó una de las importantes demandas de un racionalismo instituido en estilo internacional al arrancar la década de los años treinta, ávido de emancipar la disciplina de todo tipo de lastres obsoletos, pese a que pudiera ser considerada, a ojos de cualquier retrógrado, como arquitectura menor-cuando no indigna- por carecer del suficiente respaldo de los antiguos tratados; no así para Hitchcock y Philip Johnson, quienes sostuvieron que: "In the last decade it has produced sufficient monuments of distinction to display its validity and its vitality. It may fairly be compared in significance with the styles of the past" ${ }^{20}$, asimilándolo al gótico en los aspectos estructurales y al clasicismo en los formales. Entre otros acontecimientos, la Exposición Internacional de París de 1937 certificaría el renovado espíritu de muchos países, pese a la oposición de algunos gobiernos autoritarios, como los de la antigua URSS y Alemania, cuyos pabellones vecinos, diseñados por Boris lofan y Albert Speer respectivamente, daban la nota discordante, presumiendo de un realismo socialista y un clasicismo prusiano de suma grandilocuencia, ilustrativo de lo que Franco Borsi ha denominado orden monumental21, de tenaz predilección para las dictaduras. Por otro lado, el rechazo moderno al pasado generó una total indiferencia con relación a la ciudad existente; los nuevos crecimientos urbanos se basaban en áreas residenciales de bloques exentos que desterraron la tipología de manzana cerrada y, consiguientemente, la secuencia 
lineal de fachadas, suprimiendo cualquier motivo plástico, lo que contribuyó a despersonalizar el espacio público en tal grado que cualquier suburbio reproducía la misma imagen anodina sin importar su emplazamiento.

Dicha coyuntura hizo que, en la misma fecha, un elenco de arquitectos y críticos se decantaran explícitamente en esta materia. Entre ellos, Walter Curt Behrendt se pronunció bajo el epígrafe Disqualification for the monumentak2, donde reconoce los avances tipológicos acaecidos en edificios con programas funcionales concretos, pero no así en los de índole monumental, pese a las experimentaciones practicadas incluso con iglesias modernas, que no superaban la consideración de manifestaciones irrelevantes cuya definición quedaba limitada a una imagen externa con innovadores materiales, pero sin apelar a un mínimo sentido religioso, hasta el punto de que alguna de las cuales fue tildada de "almacén de almas», lo que el germano achaca a una extendida crisis de pensamiento que hacía que ninguna idea política, económica o artística obtuviera un general consenso. Una falta de creencia en lo absoluto como causante psicológica que, a su juicio, venía acompañada de otra no menos importante de raíz sociológica, en tanto que: "Whereas an aristocratic society indulges in erecting all kinds of monuments, using them as symbols to impress on the people the static character of the social building, a democratic society whose structure, based on the concept of organic order, is of dynamic character has no use, and therefore no desire, for the monument" ${ }^{23}$. No obstante, admite la consecución de un resultado adecuado en contadas excepciones, como la audaz intervención de Heinrich Tessenow para reacondicionar la Neue Wache de Karl Friedrich Schinkel en Berlín a cenotafio-homenaje a los caídos durante la Primera Guerra Mundial (1931), consistente en un simple espacio vacío iluminado por un óculo cenital abierto bajo el que se situaba un bloque de granito con una corona funeraria de bronce, cuya atmósfera es igual de impactante que severa, dejando constancia de la primacía moderna de lo sobrio frente a lo exuberante, de lo rompedor frente a lo convencional (fig. 3).

Y, en la misma línea, Lewis Mumford remataría la cuestión con su artículo The death of the

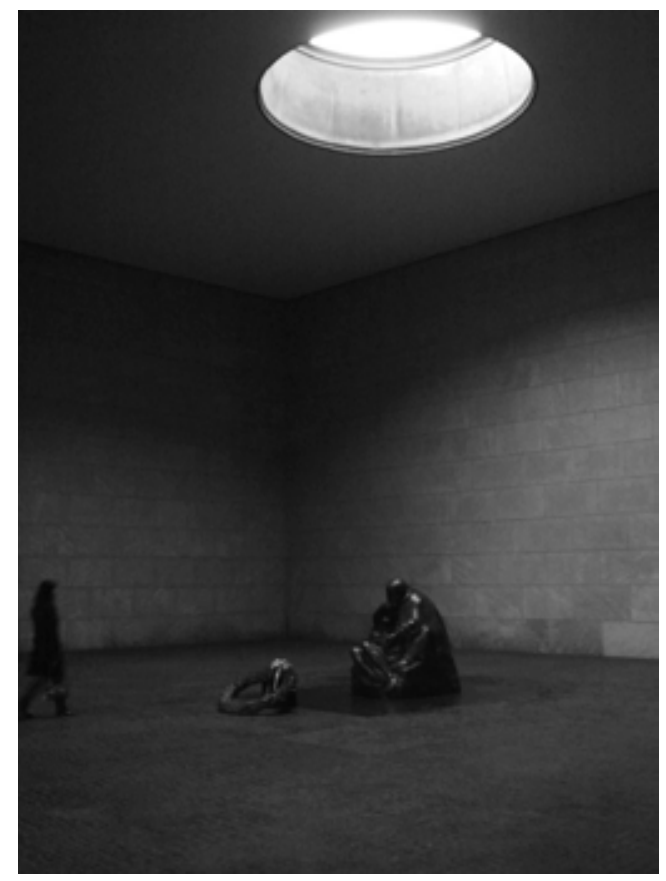

Fig. 3. Heinrich Tessenow: adaptación de la Nueva Guardia a memorial (1931), actualmente dedicado a las víctimas de la guerra y la tiranía -con el añadido reciente de una réplica ampliada de la escultura Madre con hijo muerto (o Pietá) de Käthe Kollwitz-. Fuente propia

monument en 1937 - formando parte de una colección de ensayos de arte y arquitectura publicada en Londres -, que sería reeditado al año siguiente dentro de su fundamental obra The culture of cities ${ }^{24}$, donde afirmó que siempre, en civilizaciones anteriores, ha existido el deseo de erigir monumentos sólidos e inertes, como signo de consideración y respeto hacia el tema de la muerte. Un crucial desenlace que justifica el afán constante por perpetuar a los vivos, intentando desafiar el implacable paso del tiempo, lo que se ha instrumentalizado mediante la creación de objetos supuestamente imperecederos, con frecuencia resultantes de procesos de «momificación arquitectónica», nacidos de la vanidad de ricos y poderosos, atormentados por lograr su inmortalidad aunque fuera petrificada en pirámides, templos, panteones... lo que ha ido convirtiendo la ciudad, con su amalgama de edificios marchitos, en un auténtico y gigantesco cementerio, dando una falsa percepción de continuidad. Ahora bien, según Mumford, los últimos siglos han originado un profundo cambio de la 
concepción biológica que despoja al monumentalismo de su significado principal, por cuanto la humanidad ha reorientado su mirada hacia el ciclo de la vida. Un hecho que, unido al de haber atestiguado la fragilidad física de las obras simbólicas y la debilidad de sus poderes fundadores, reduciendo algunas formas y patrones del pasado a meras tentativas infantiles, provoca que la supervivencia material ya no represente la cultura ni las convicciones actuales.

De este modo, el Lincoln Memorial en Washington DC o el monumento a Vittorio Emmanuele II en Roma son tan solo dos claros ejemplos de «luces eternas» que se apagan, obras completamente caducas e intrascendentes para la dinámica urbana, lo que mueve a Mumford a pensar que "The very notion of a modern monument is a contradiction in terms: if it is a monument, it cannot be modern, and if it is modern, it cannot be a monument" ${ }^{25}$. Una decadencia que no solo afectaba a las construcciones de componente sacro o institucional, sino también a otros muchos equipamientos que habían adquirido la condición monumental debido a su particular efecto. $Y$ es que el estadounidense defendía que lo que verdaderamente hace que un edificio sea evocador estriba en su precisa adecuación a los nuevos hábitos y modos de vida, su idoneidad como soporte de actividad, y no en la creencia metafísica de su presunta inmutabilidad - lo cual no impide que puedan existir constantes (estándares) que sí deban permanecer. Así, la sociedad debería adoptar la mentalidad del nómada, reduciendo su caparazón fijo a lo estrictamente indispensable para, en su lugar, priorizar ambientes vivideros, lo que permitiría que las ciudades fueran organismos autorenovadores. A tal propósito, habría que impulsar desarrollos flexibles, evitando grandes inversiones en rígidas (infra)estructuras como las que suscita la metrópoli; en palabras del propio Mumford, referidas a la nueva era mecanocéntrica, "The deflation of our mechanical monuments, then, is no less imperative than the deflation of our symbolic monuments" 26 .

\section{1940-1945: inflexión durante el período bélico}

Atendidos los graves problemas de vivienda y planeamiento urbano de la etapa de entreguerras, uno de los aspectos que restaba por solventar en los años cuarenta, no menos complejo, era la recuperación de la vida comunitaria, directamente ligada a la existencia de civic centers con suficiente representatividad, no concebidos tan solo desde una óptica utilitaria sino también emotiva. A este respecto, Josep Lluís Sert, Fernand Léger y Sigfried Giedion formularon conjuntamente sus cruciales Nine points on monumentality en 1943, predestinados a convertirse en sumario del octavo CIAM dedicado a The heart of the city, que se celebraría en Hoddesdon en 1951, a pesar de que no serían finalmente publicados hasta mitad de la década siguiente ${ }^{27}$. Destaca el hecho de que el último de ellos acababa de concluir Space, time and architecture en 1941, desde una visión disciplinar puramente maquinista, a modo de historia del movimiento moderno desde sus más profundos orígenes -recopilando los seminarios impartidos tres años antes como titular de la cátedra Charles Eliot Norton en la Universidad de Harvard-, de donde se deduce un rápido a la vez que drástico cambio de enfoque; sin duda, influido por las últimas obras de Frank Lloyd Wright ${ }^{28}$, especialmente el proyecto para la sede de la compañía S.C. Johnson \& Son en Racine (1936-1939), donde su conmovedor espacio central ritmado por esbeltas columnas dendriformes le hizo ver que un edificio administrativo también podía gestarse a partir de un planteamiento con tinte poético. Una línea acentuadamente revisionista en la que también se posicionaría Sert, en su caso tras la publicación aún más reciente de Can our cities survive? ${ }^{29}$ en 1942, como recopilación de las conclusiones extraídas del cuarto y el quinto CIAM - celebrados en 1933 y 1937 respectivamente -, cuya introducción corrió a cargo del suizo. El propio Giedion relata la génesis del escrito recordando cómo, durante uno de sus encuentros en Nueva York, con el doloroso trasfondo del exilio, descubrieron casualmente que los tres (historiador, pintor y arquitecto-urbanista) habían sido invitados por la asociación American Abstract Artists - de la que Léger era notorio miembro para exponer los temas que les suscitaran mayor interés, mediante sendos artículos a publicar en su bisoña revista ${ }^{30}$. Una circunstancia que les hizo consensuar la conveniencia de abordar un mismo contenido a partir de sus diferentes perspectivas 
profesionales: la nueva monumentalidad, lo que resumieron en casi un decálogo ${ }^{31}$.

Encabezado por versos de una popular marcha militar francesa compuesta a principios del siglo XVIII, que nos transmite la majestuosidad de las más sublimes obras arquitectónicas de la capital gala, prueba del sentimiento de pérdida que invadía a los refugiados europeos tras el nuevo estallido armado, el manifiesto refleja el fracaso generalizado tanto de la supuesta monumentalidad de la Nueva Tradición como del funcionalismo del movimiento moderno para representar las aspiraciones comunes de las gentes, así como deja entrever que la expresión de su historia y valores colectivos solo puede ser realizada a nivel local, pues los grandes Estados centralizados o autoritarios son incapaces de encarnar alegóricamente las esperanzas del pueblo ${ }^{32}$. Así, una vez sentado el concepto de monumento en sus dos primeros puntos, como piedras miliares donde los hombres crearon símbolos para sus ideales, objetivos y actividades, con vocación de legado, expresando las más altas necesidades culturales, seguidamente se diagnostica la falta de obras catalizadoras de estas fuerzas conjuntas desde mitad del siglo XIX, pues los intentos habidos se revelan como cáscaras vacías sin el espíritu de la época. Del quinto punto en adelante se aporta la solución: los edificios deben nacer de una planificación global, donde se reorganicen y reactiven los centros urbanos, con lugares abiertos que acojan equipamientos públicos no solo funcionales sino también exaltadores, lo que requiere aglutinar el trabajo de arquitectos, pintores, escultores y urbanistas, cuya colaboración era inexistente desde las primeras décadas ochocentistas, al mismo tiempo que arbitrar criterios políticos sin prejuicios artísticos, donde quepan recursos y materiales modernos que transformen las construcciones - con juegos de sombras arrojadas por objetos móviles, proyecciones coloristas, etc. - combinados con elementos naturales como vegetación y agua, de los que resulte un cuadro total que recobre el escenario lírico.

En este sentido ahondaría Fernand Léger, durante ese mismo año pero de manera individual, por medio de su ensayo On monumentality and color ${ }^{33}$, donde también propugna la síntesis de las artes con la arquitectura moderna como directora de orquesta, vaticinando que uno de los retos más emocionantes, a partir de aquel momento, iba a ser la evolución que debían sufrir las superficies murales a través del empleo del cromatismo puro, toda vez que se hubo percatado de nuevas posibilidades para reorientar adecuadamente la pintura, mediante las que era posible evitar el carácter muerto y anónimo que exhibe cualquier pared desnuda. Para actuar sin ningún tipo de restricción, el primer paso era desligar al color de su asociación con objetos o formas predeterminadas, como evolución del neoimpresionismo desarrollado en décadas anteriores, lo que ya habían experimentando artistas como Robert Delaunay desde principios de siglo y, sobre todo, de lo que se estaba aprovechando un mundo publicitario que irrumpía con fuerza en toda clase de vías públicas con la consiguiente definición de un renovado paisaje. Así, tanto el exterior como el interior de los edificios tomarían nuevos derroteros, apropiándose de un efecto dinámico que ya había anticipado Le Corbusier en 1946 mediante el concepto de espacio indecible ${ }^{34}$; todo volumen construido, así como su peso y distancia, pueden disminuir o aumentar de acuerdo a las tonalidades que le sean asignadas.

Derivado de lo anterior, el francés se pregunta, extrapolando a una mayor escala, ¿por qué no realizar también una configuración polícroma de una calle o una ciudad? Y es que pensaba que los desarrollos residenciales para clase media eran los que más evidenciaban dicha necesidad, en la medida que requerían un incremento aparente (al menos) de espacio, así como los centros urbanos. Para estos últimos concebía monumentos espectaculares, móviles y cambiantes - manifestando atractivos e intensos significados -, donde color y luz articularan el conjunto, lo que les dotaría de la misma relevancia que cualquier templo o iglesia, gracias a los resultados psicológicos que producen, ya sean conscientes o inconscientes, capaces de transformar el estado de ánimo - y, consecuentemente, los hábitos - de una sociedad, por cuenta de matizar la cruda realidad con un deseado equilibrio entre verdad y fantasía. Ejemplo de ello fueron sus charlas con Leon Trotsky, quien pretendió llevarle a Moscú para crear dos calles ambientadas en azul y amarillo. O su más tardía propuesta, para la Exposición Universal de París de 1937, de convertir la capital en una ciudad 
blanca y radiante mediante el tratamiento de todas sus fachadas, que serían bañadas por haces de colores proyectados al atardecer desde la torre Eiffel y aeroplanos, entre acordes musicales, lo que finalmente se desestimó por el excesivo conservadurismo, a ojos de Léger, que mostraban los ciudadanos hacia una vetusta imagen urbana.

Todo este despliegue argumental se vería ampliado con las explicaciones que Giedion desarrolló bajo el título The need for a new monumentality35, para el simposio New architecture and city planning celebrado en Nueva York un año después, levantando numerosas críticas por cuanto reavivaba conceptos absolutamente desvirtuados que entrañaban un notable riesgo. Entre ellas destaca la opinión discordante de Lewis Mumford que llegó, incluso, a publicarse en The New Yorker, sin que finalmente disuadiera al suizo de reiterar sus pertinaces alegatos en distintas conferencias, tanto en foros americanos como europeos. Éste proclamaba que el anhelo de monumentalidad se trata de algo imposible de extinguir, pues resulta inherente a nuestra propia especie, independiente de los regímenes gubernamentales; surge de la eterna necesidad del hombre de crear símbolos en los que se reflejen sus acciones y destino, así como alienten sus convicciones sociales y religiosas, transmitiendo apasionados recuerdos a las generaciones venideras, despertando el sentimiento inconsciente de la población - profundamente dormido por aquellas fechas - a través de una novedosa concepción imaginativa del espacio público de convivencia, favorecida por la participación de todas las artes, cuya síntesis muestra mayores posibilidades debido al aumento de los recursos técnicos disponibles. La esencia de lo monumental había sufrido una profunda evolución durante la primera parte del siglo XX; desde entonces había que buscarla en la incontestable configuración espacial. Uno de los mejores paradigmas sería la Ciudad Universitaria de Caracas, que se empezó

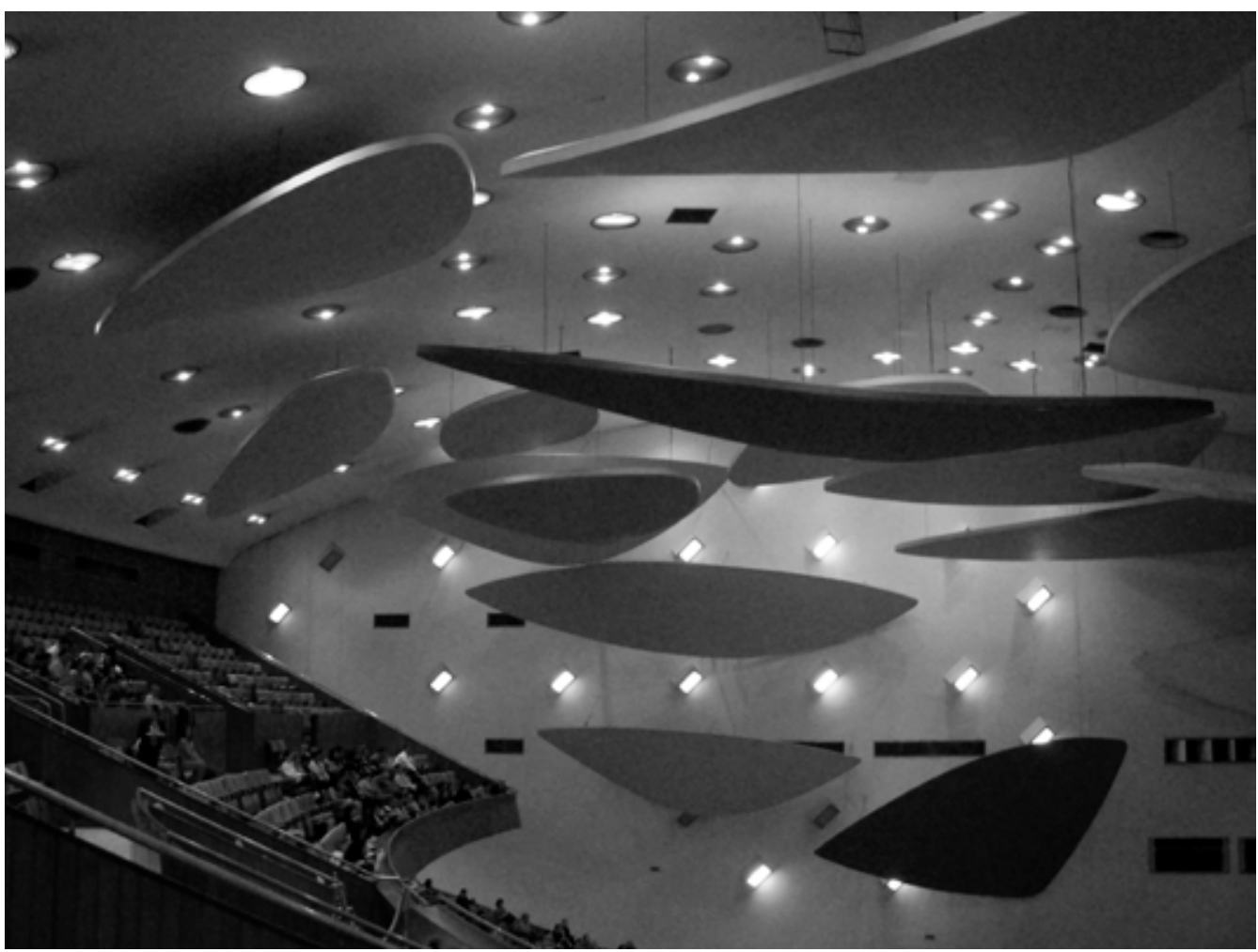

Fig. 4. Carlos Raúl Villanueva: Aula Magna de la Universidad Central de Venezuela en Caracas (1952-1953); interior de la sala con las nubes acústicas colgantes de Alexander Calder. Fuente: Dodeckahedron (https://flic.kr/p/5XSaH2) 
a proyectar en 1944 por Carlos Raúl Villanueva, cuyo conjunto central para uso administrativo y cultural (1952-1953) incorpora obras de innumerables artistas como Jean Arp, Antoine Pevsner y Alexander Calder (fig. 4).

Otro de los participantes en el encuentro fue Louis I. Kahn, quien también se pronunció, en su caso, bajo el escueto epígrafe Monumentality ${ }^{36}$, entendiendo que hace alusión al carácter inmortal de algunas obras, el cual no puede añadirse o cambiarse. Una cualidad espiritual cuya incorporación a la arquitectura moderna entrañó serias dudas por la extrema relatividad que caracteriza a nuestro mundo reciente, imposible de expresarse con una mera fuerza intencional, así como por el enigmático hecho de que no pueda ser atribuible deliberadamente; ni el mejor material ni la tecnología más avanzada pueden garantizarla, pese a que los monumentos siempre hayan mostrado una perfección estructural que redunda en forma, proporción y tamaño adecuados, además de sensación de permanencia. La historia nos aporta una sabia lección: la construcción griega se basaba en pórticos adintelados que la romana sustituiría por arcos, bóvedas y cúpulas, trabajando a compresión, mediante los que se dilató el espacio interior; la medieval idearía contrafuertes, arbotantes y pináculos para contrarrestar empujes, con cargas transmitidas a través de nervaduras, permitiendo elevar y horadar muros; el siglo XIX gestaría las estructuras reticuladas, metálicas y de hormigón, expresivas del diagrama de fuerzas, con perfiles cuya forma (tubular, doble ${ }^{\prime} T^{\prime}$...) nace de su óptimo comportamiento mecánico, también a flexión. Así, el estadounidense pensaba que los nuevos monumentos, conmemorativos de logros y aspiraciones actuales, no deben erigirse del mismo modo que antaño, sino aplicando la ciencia, con innovadores sistemas constructivos.

Con este planteamiento, la arquitectura redefine el sentido de cada uno de sus elementos así como su relación de conjunto, suministrando mayores potencialidades a disposición del diseñador, acordes a la sensibilidad de su tiempo, que nada tienen que ver con discutibles dogmas, criterios vetustos o estándares arbitrarios. Todo ello de un modo equilibrado, sin menoscabo de la rica tradición, como bien demuestra su presti- giosa obra, mayoritariamente concebida tras su decisiva estancia en Roma con cincuenta años de edad, donde aprendió la belleza clásica y su esencia de 'presente eterno' ${ }^{37}$; la Yale University Art Gallery en New Haven, Connecticut (19511953) y los laboratorios médicos Richards en Filadelfia (1957-1961) son tan solo algunos de los primeros ejemplos que posteriormente avalarían lo expuesto, donde se desprende un cierto deseo por volver a los arquetipos, incluso retomando conceptos característicos de las construcciones antiguas, aunque sin constituir un sistema de símbolos puesto que no permiten variaciones y combinaciones. Edificios que se muestran igual de solemnes que intemporales, divinos a la vez que humanos - con juegos a doble escala -, modelando ideas universales mediante geometría elemental, y ejecutados armoniosamente a través de escenografías de luz y materiales con el mismo brutalismo que precisión.

Todos estos pronunciamientos, así como otros inmediatamente posteriores, fueron causa directa del fuerte impacto producido por la Segunda Guerra Mundial, cuya capacidad destructiva fue ilimitada. Una de las más notables secuelas, para George Mosse, consistió en la desaparición del mito de la experiencia de la guerra ${ }^{38}$, lo cual supuso que no hubiera argumentos para justificar recordatorios heroicos, ni tan siquiera en los países victoriosos. Un vuelco ideológico que dio pie a repensar en alternativas arquitectónicas, carentes de lecturas peyorativas y, por tanto, gestos grandilocuentes, aprovechando la expansión generalizada del programa de los living memorials (monumentos vivos) - ya ensayados parcialmente durante el período de entreguerras en EE.UU. - ${ }^{39}$, que pretendía erigir equipamientos donde mezclar la finalidad conmemorativa con el uso práctico, en aras de celebrar la única consecuencia positiva de la contienda, como logro alcanzado a nivel de ideales: disfrutar la democracia y su repercusión de libre acceso a educación, cultura, deporte, etc. por medio de escuelas, bibliotecas, parques y jardines, campos de juego... predestinados a dinamizar los centros cívicos. Pero, según advirtió Philip Johnson ${ }^{40}$, no bastaba con denominar conmemorativa a una construcción para convertirla en tal, sino que se precisaba enriquecer el lenguaje formal de la arquitectura para propor- 
cionar una respuesta conjunta, no solo utilitaria sino también emotiva.

\section{1945-1960: ideología renovada de pos- guerra}

Inmediatamente después de la contienda militar, en el sexto CIAM celebrado en Bridgwater en 1947, aún no mostraría gran resonancia el nuevo sesgo infligido en materia de monumentos, que continuaban ligados básicamente al ámbito conmemorativo, como demuestra la antología exhibida con proyectos como el War memorial en Cambridge, Massachusetts (1945) de Marcel Breuer; el Monumento ai caduti nei campi di sterminio nazisti en el cementerio Monumental de Milán (1946) de Belgiojoso, Peresutti y Rogers; o el imponente Gateway Arch en St. Louis (19471968) diseñado por Eero Saarinen (fig. 5). Sin embargo, la ponencia impartida por Giedion en el Royal Institute of British Architects, el 26 de septiembre de este último año, sobre La necesidad de una nueva monumentalidad, propició que los editores de The Architectural Review decidieran tratar el tema pormenorizadamente en 1948, mediante el importante simposio In search of a new monumentality, que reuniría los dictámenes de algunos de los más prestigiosos expertos, concretamente Gregor Paulsson, Henry-Russell Hitchcock, William Holford, Walter Gropius, Lucio Costa, Alfred Roth y el propio helvético, compilados en un capítulo completo de la revista ${ }^{41}$, donde expusieron el significado que dicho concepto desprendía para cada uno de ellos, así como su posible encaje dentro del panorama internacional de la disciplina en aquel instante. En vías de superación de la crisis económica que había confinado las obras a un estricto funcionalismo material, mayoritariamente les parecía el momento apropiado para que la arquitectura moderna comenzara a ejercitar sus habilidades en el desarrollo de un vocabulario más prolijo, expresión necesaria de ideas y sentimientos colectivos, enriqueciendo lo utilitario con lo moral y emotivo, a la vez que reconciliándose con detractores surgidos por controversias reminiscentes.

A tal fin, lo primero era determinar en qué consiste la monumentalidad, término usado con muy distintos matices (incluso ambigüedad) en el pasado, lo que indujo a Paulsson a recordar que su viejo empleo latino nunca iba asociado con aspectos edilicios o estéticos - para los que se recurría a otro tipo de expresiones tales como dignitas o maiestas, además de adjetivarse con los calificativos de magnificus, splendidus o decorus. Hitchcock, sin embargo, haría hincapié en

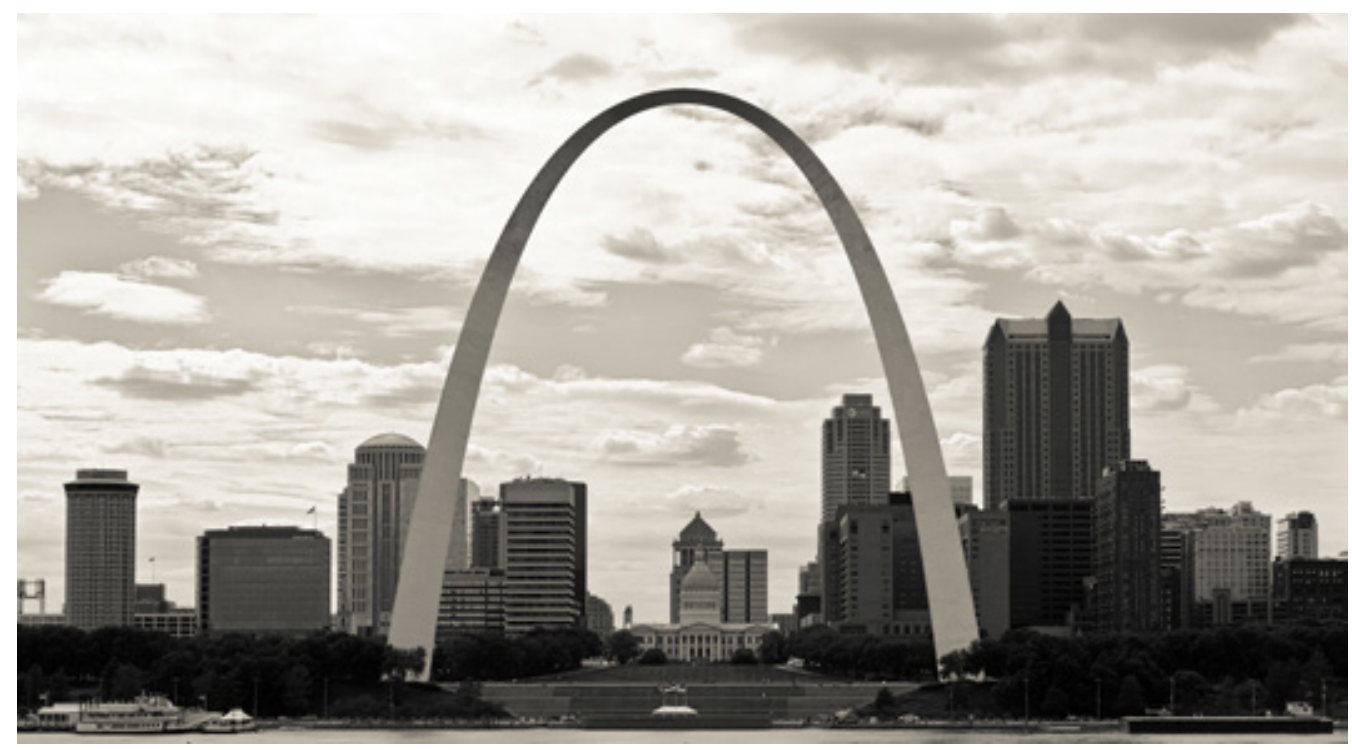

Fig. 5. Eero Saarinen: Arco Gateway -simbolizando la «Puerta hacia el Oeste»-, St. Louis (1947-1968); panorámica desde la ribera opuesta del río Misisipi. Fuente: Daniel Wormek (https://flic.kr/p/9Jzv3C) 
que, pese a quedar popularmente circunscrita solo a memoriales o panteones, su ámbito viene extendido por los historiadores a cualquier construcción remota, dando por sentado que su carácter testimonial (consciente o no) es común para todos los casos; algo que entronca con el parecer de Gropius, Giedion y Roth al subrayar el sentimiento perfectamente descrito por John Ruskin cuando escribe: "Consider [...] whether we ought not to be more in the habit of seeking honour from our descendants than our ancestors; thinking it better to be nobly remembered than nobly born" 42 . Asimismo, aceptadas por amplio consenso, se atribuyen otras cualidades a lo monumental; una de ellas es la «durabilidad», en estrecha relación con la solidez, que tiene que ver con lo pesado e inmóvil, aunque Gropius puntualiza que se debe admitir el equivalente moderno de una nueva estructura física para un modo más elevado de vida cívica, caracterizada por la continua evolución y flexibilidad hacia el crecimiento, lo que Holford respalda en tanto que considera el tiempo como una de sus nuevas variables, no ignorada ni combatida; entre las restantes propiedades se encuentra la «dignidad», materializada por lo sereno, unitario y de ritmo lento, así como la «gran escala».

No obstante, lo importante es que siempre haya repercusión emocional, otorgando un mayor alcance al concepto de monumentalidad que al de monumento, lo que atestigua el hecho de asignar aquella a numerosas obras ingenieriles, tan paradigmáticas como el puente Golden Gate en San Francisco, aparte de a modernos complejos arquitectónicos, entre los que sobresale el Rockefeller Center en el corazón de Manhattan, ambos de flamante construcción por entonces. Es bastante significativo el que, por el contrario, Hitchcock rechace esta característica en otros edificios plenamente innovadores y singulares, como el Crystal Palace en Londres, debido a su manifiesta condición efímera, que ofrece la lectura de un precario conjunto de elementos, al tiempo que Giedion sí admite que se adjudique a grandes espectáculos capaces de fascinar a la población, celebrados dentro de los centros cívicos, citando el ejemplo de los juegos de agua y fuegos artificiales de las Exposiciones Internacionales de París de 1937 y Nueva York de 1939. Otro punto de divergencia se suscitó a propósito de la monu- mentalidad simulada o seudomonumentalidad, que Holford reivindica - sin mencionarla expresamente - como un sano intento de recuperar los criterios compositivos clásicos, lo que Giedion descarta completamente por su esencia desvirtuada. Con relación a ello, también sin apoyo mayoritario, Paulsson cree que surge normalmente en sociedades democráticas mientras que la genuina lo hace en regímenes autoritarios, como bien demuestra la historia a través, entre otros, de los imperios francés y alemán.

A partir de lo anterior, el siguiente paso era dilucidar si la monumentalidad resulta deseable y, en su caso, qué papel debe jugar y cómo alcanzarla. A este respecto, casi todos se manifiestan claramente a su favor, con Giedion apremiando a que la arquitectura moderna recorra este camino que, bajo su criterio, no solo es el más peligroso sino también el más difícil, pero imprescindible para colmar las aspiraciones colectivas de regocijo, boato y emotividad. Una opinión frontalmente opuesta a la de Paulsson, quien acude a la historia del Renacimiento italiano escrita por Jacob Burckhardt, para recordar que dicho estilo surgió de ambiciosos déspotas que pretendían autogloriarse mediante construcciones representativas de su poder, incitando admiración y temor, lo que no tiene encaje en la libre sociedad actual, aunque los nuevos materiales y sistemas constructivos así lo permitan y una parte del funcionalismo también consista en colmar los anhelos expresivos de riqueza y sometimiento. En nuestra época, según el profesor de la Universidad de Uppsala, esa no debe ser la prioridad, sino mejorar las condiciones ambientales del entorno físico que habitamos, donde los espacios libres y las zonas verdes - con un trazado humanizado - asuman notable protagonismo, lo que sí podría relacionarse con los centros cívicos pero desde su lectura amplia y renovada; una idea que Lucio Costa respalda, pero sin renunciar a la monumentalidad derivada de una correcta elección de volúmenes, tamaños y proporciones, posible para cualquier tipo de edificación, incluso industrial. Por su lado, Giedion piensa que la clave de su logro reside en crear dichos centros a partir de una estrecha colaboración entre arquitectos, pintores y escultores, mientras que Hitchcock y Roth apuntan a un adecuado diseño urbano en el planeamiento urbanístico, lo que Holford y Gropius no entienden 
como algo inmediato pues dependerá de que, lentamente, vaya calando un sentimiento popular de perpetuación con el transcurso del tiempo.

En definitiva, toda una larga serie de reflexiones que Talbot Hamlin, profesor de la Universidad de Columbia, consideró rotundamente "among the most significant contributions to recent architectural criticism", según hizo constar en Progressive Architecture en febrero de $1949^{43}$. Una revista que, tan solo dos meses antes, había vuelto a divulgar el mismo posicionamiento de Paulsson, discrepante respecto al de sus compañeros, esta vez mediante una versión más contundente y pragmática de su rechazo a la monumentalidad en tanto que seguía vinculándola con anticuados absolutismos. Circunstancia que provocó una oleada de escritos de contestación en números siguientes, llovidos desde distintos puntos de EEUU; algunos claramente de apoyo, por cuenta de Gardner A. Dailey y Ernest Kump (San Francisco), así como William Wurster y Robert W. Kennedy (MIT); frente a otros muchos decididamente en contra, de Christopher Tunnard y Carroll L.V. Meeks (Universidad de Yale), Philip Johnson y Peter Blake (MoMA), además del correspondiente al ya mencionado Hamlin ${ }^{44}$. En paralelo, el editor, Thomas H. Creighton, abogaba porque los monumentos de nuestro tiempo fuesen edificios como hospitales, escuelas y hasta viviendas, puestos al servicio del pueblo, y no palacios, templos y arcos de triunfo para emperadores o aristócratas.

Por último, ese mismo año pero nuevamente en The Architectural Review, también Lewis Mumford tendría ocasión de añadir su opinión, como una adenda al simposio previamente organizado, mediante el artículo Monumentalism, symbolism and style, donde se ratificaba en que la modernidad había renunciado a la mayoría de símbolos históricos, así como devaluado el monumento en sí mismo por cuanto negaba los altos valores que representa, lo que impedía crear otros nuevos que fueran convincentes. El único símbolo cuya validez reconoció, con carácter casi generalizado, era el instituido por la «máquina», especialmente a partir de su consagración tardía por Le Corbusier en 1923; momento en el que, pensando en términos de objetividad, economía y eficiencia, se quiso dotar a los edificios de un aspecto fabril de igual modo que, por motivos distintos, se había buscado su semejanza con iglesias o palacios en otras épocas. Una visión mecanicista que, tras la Segunda Guerra Mundial, se comenzó a percibir excesivamente reduccionista, más si cabe cuando ya entraba en decadencia, dejando paso a un irrefrenable anhelo de humanización. En todo caso, lo que debe importar son las intenciones sociales que subyacen en la obra y no la tenencia de unos peculiares rasgos morfológicos o decorativos; en palabras del propio Mumford, se podría decir que:

In essence, the monument is a declaration of love and admiration attached to the higher purposes men hold in common [...]. Most ages, to make the monument possible, have (in Ruskin's terms) lighted the lamp of sacrifice, giving to the temple or the buildings of state, not their surplus, but their very life-blood.... ${ }^{45}$.

Así concluiría la primera mitad del siglo XX, con nuevas pautas servidas respecto a una ciertamente cuestionada monumentalidad que, según Christian Norberg-Schulz, no se llegó ni siquiera a consumar durante esta etapa por cuanto adoleció de una imagen arquitectónica de vigencia universal, entendiendo que una forma construida se convierte en ella "cuando revela un modo típico de estar [...], una estructura básica de la espacialidad existencial"; la pirámide, el arco, la cúpula y el frontón fueron paradigmáticos porque revelaban las relaciones entre el arriba y el abajo, el aquí y el allá, de una manera reconocible, con capacidad para crear lugares, mientras que las obras modernas, para el noruego, se movían "entre la generalización abstracta y la particularización atípica" ${ }^{46}$. Un rasgo que tampoco se vería modificado en la mayoría de intentos postreros, según aquel, incluso con edificaciones teñidas de un renovado expresionismo, como la capilla de Notre-Dame du Haut en Ronchamp (1950-1954) de Le Corbusier, magistral obra de arte pero nacida de una solución singular sin suficiente valor tipológico. No obstante, su capitolio para Chandigarh (1951-1958), así como el ideado en Brasilia D.F. (1956-1960) por Oscar Niemeyer, definiendo sendas cabeceras urbanas, evidencian un equilibrio entre memoria e innovación con el que adquieren la condición de acrópolis contemporáneas; en este último caso, reinterpretada por 


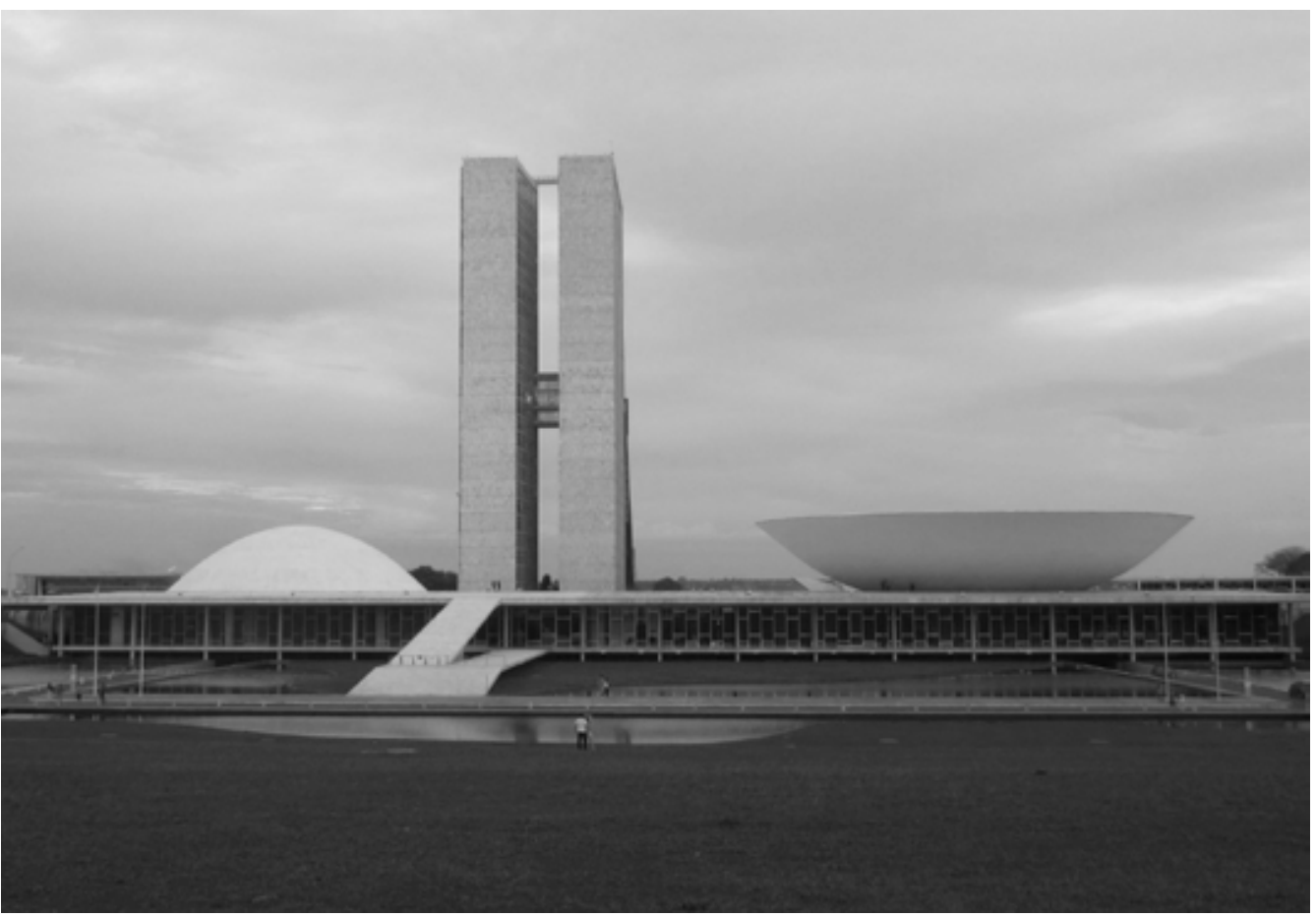

Fig. 6. Oscar Niemeyer: Congreso Nacional, Brasilia D.F. (1958), de cuya plataforma horizontal arrancan dos vertiginosos bloques de veintisiete plantas que rematan el Eixo Monumental de la ciudad. Fuente: Francisco del Corral

medio de cúpulas contrapuestas a la tipología moderna de torre (fig. 6).

Precisamente, a propósito de las edificaciones en altura, hay que señalar que, relegados los poderes tradicionales por la abrumadora primacía de los poderes económicos y, en consecuencia, perdidos muchos de los parentescos políticos y religiosos de los monumentos existentes, a principios de los cincuenta ya se habían alzado voces para reconocer otras de sus formas de concreción en esta nueva coyuntura, rompiendo con las convenciones simbólicas, como la de José María Sostres, que tuvo eco en la Revista Nacional de Arquitectura ${ }^{47}$. Es el caso de los rascacielos, impuestos en la sociedad capitalista como señal inequívoca de ostentación y privilegio, calificados de verdaderas «catedrales del dinero», más por significado que por tamaño, cuyo nombre deriva frecuentemente de las empresas y patronos más influyentes del mundo - la Lever House y la sede central del Chase Manhattan Bank en Nueva York (1951-1952 y 1957-1961) de Skidmore, Owings y Merrill con Gordon Bunshaft; la torre Pirelli en
Milán (1956-1958) de Gio Ponti y Pier Luigi Nervi... -, intimidando con su mayestática presencia, de rotundo lenguaje propio, en los distritos de mayor especulación del suelo, para reafirmar su notoriedad y estatus a la vez que insinúan el sometimiento colectivo al imperio financiero. El arquitecto catalán advierte que el skyscraper integra factores de nuestra época bastante específicos, como romanticismo técnico, publicidad y calidad representativa, que lo han dotado de una sintaxis propia. Así, desde los primeros edificios de Chicago, experimentaciones del hierro laminado pudorosamente revestidas de historicismo, el rascacielos se ha ido liberando hasta incorporarse a lo monumental en términos autóctonos.

Pese a ello, a juicio de Norberg-Shulz, tendría que llegar la posmodernidad para conseguir la definitiva recuperación de la imagen tipo. Pero no se trataba de revivir el historicismo combatido por la arquitectura moderna, sino de la posibilidad abierta por Louis $\mathrm{H}$. Sullivan de poder retornar al ornamento después de un paréntesis en el que se concentrara el esfuerzo en producir obras 
bien formadas y agradables en su desnudez; una vuelta que solo sería sustanciosa manteniendo la nueva concepción del espacio ${ }^{48}$. Y es que, de acuerdo a Sostres, el concepto de monumentalidad satisface "una necesidad que tiene su centro en profundos estratos del alma colectiva. Son problemas que responden tanto a lo existencial como a la esencia intemporal del hombre. Vinculan la creación material al sentimiento del más allá, a una conciencia de época y de agrupación, son alusiones al futuro" 49 . En definitiva, el instinto de supervivencia de nuestra especie potencia el sentimiento de continuidad también patrimonial.

\section{Conclusiones}

La controversia en torno a la monumentalidad, erigida en detonante básico del estallido racionalista, constituyó asunto clave durante la primera mitad del pasado siglo, cuando se censuró la retórica ecléctica, mostrando continuidad en el devenir moderno con dos fases disociadas por la Segunda Guerra Mundial. Así, a partir de la renovación teórica de Riegl y las extremas restricciones planteadas por Loos, con un simbolismo cada vez más circunscrito a la estricta representación del espíritu de la época, antagónico a toda clase de modelos pasados, el único reducto que subsistiría con cierta fuerza monumental, frecuentemente no reconocida por los negativos prejuicios inherentes al término, vino de la expresión honesta que comportaban las nuevas técnicas derivadas de los avances industriales, cuya contundencia formal era equiparable a la propia de la antigüedad, ahora implícita en las construcciones ingenieriles, especialmente americanas, consagradas durante los años diez y veinte de manera sucesiva por Gropius, Sant'Elia y Le Corbusier, donde los neoplasticistas Oud y van Doesburg hallaron la premisa de una deseada confluencia artística. Así, el estilo internacional acabó diezmando el monumentalismo más académico, incluso en su remozada versión de los Nuevos Tradicionalistas, desde la primacía de un funcionalismo que solo fue compasivo con depurados aspectos plásticos y vernáculos. Behrendt y Mumford certificarían su indiscutible defunción a finales de los treinta, tras constatar la absoluta pérdida de su significado histórico en una sociedad completamente transformada.

No obstante, la doctrina moderna se vería reconducida categóricamente por Giedion, Léger y Sert con sus decisivos Nine points en 1943, con un trasfondo bélico que hizo tambalear la cultura europea, donde la memoria colectiva debía blindarse como aval. De este modo, la nueva monumentalidad irrumpió como drástica respuesta, basada en una síntesis de las artes que aunaría a arquitectos, pintores, escultores y urbanistas, para recuperar la identidad y el sentimiento colectivos de la población, activando su mermada vida comunitaria principalmente a través de renovados centros cívicos, cuyo amplio análisis se pospondría al octavo CIAM. Un determinante giro que, en tan solo un año, sería corroborado individualmente en distintos textos y conferencias por parte de sus impulsores, así como secundado por Kahn desde una óptica de predominancia técnica. Ello desencadenó una ardua discusión mediática que contrapondría la postura adversa de Paulsson, al asociar monumento con despotismo, frente al sentir favorable de Hitchcock, Holford, Gropius, Costa y Roth respecto a la necesidad de recobrar el impacto emocional, ya sea en lo arquitectónico como en lo urbano; dos corrientes enfrentadas a los que se irían añadiendo adeptos. En cualquier caso, el lenguaje maquinista, después de la contienda militar, resultaba demasiado excluyente, sobre todo para la consecución de los más altos objetivos, lo que reavivó un simbolismo que empezaría incluso a vislumbrase, de acuerdo a Sostres, en tipologías singulares como el rascacielos. La monumentalidad estaba nuevamente instaurada, pero esta vez desde una profunda evolución que había reemplazado las convenciones estilísticas por una contemporánea a la par que rica configuración espacial y fenomenológica. 


\section{NOTAS}

1 El presente texto se ha gestado dentro del Proyecto I+D HAR201231133 Arquitectura, escenografía y espacio urbano: ciudades históricas $y$ eventos culturales del Ministerio de Ciencia e Innovación, partiendo del trabajo realizado por el mismo autor en la reseña "Nine points on monumentality': un manifiesto para la reactivación urbana contemporánea", publicada como parte de Josep Lluís Sert, Fernand Léger, Sigfried Giedion, "Nueve puntos sobre monumentalidad", URBS. Revista de Estudios Urbanos y Ciencias Sociales, trad. de José María Coco Ferraris y comentario de Emilio Cachorro Fernández, vol. 5, 2, 2015, pp. 197-206 [disponible en http://www2.ual.es/urbs/ index.php/urbs/article/view/cachorro], cuyos contenidos son base del desarrollo anteriormente expuesto a partir de los años cuarenta -mayoritariamente incluido en el apartado 3.

${ }^{2}$ Véase Sigfried Giedion, Arquitectura y Comunidad, Nueva Visión, Buenos Aires, 1963, pp. 33-59 [1956].

${ }^{3}$ Aloïs Riegl, Der moderne denkmalkultus. Sein wesen und seine entstehung, Braumüller, Viena y Leipzig, 1903.

${ }^{4}$ Concepto acuñado, en materia musical y escénica, por Richard Wagner a mediados del siglo XIX, que más tarde fue refrendado por Nietzsche en El Nacimiento de la tragedia (1872).

${ }^{5}$ Adolf Loos, "Architektur", 1910, tr. al castellano como "Arquitectura", en Adolf Opel, Josep Quetglas (eds.), Adolf Loos. Escritos II 1910/1932, El Croquis, Madrid, 2004, pp. 23-35.

${ }^{6}$ Walter Gropius, "Monumentale kunst und industriebau", 1911, en Karin Wilhelm (ed.), Walter Gropius, industriearchitekt, Vieweg, Braunschweig y Wiesbaden, 1983, pp. 116-120.

${ }^{7}$ Walter Gropius, "Die entwicklung moderner industriebaukunst", en Jahrbuch des Deutschen Werkbundes. Die kunst in industrie und handel, Diederichs, Jena, 1913, pp. 17-22.

${ }^{8}$ bbidem, p. 22. Tr. (extraída de Reyner Banham, La Atlántida de hormigón, Nerea, Madrid, 1989, pp. 189-190): "El convincente monumentalismo de los elevadores de grano canadienses o sudamericanos, las carboneras construidas para las principales compañías de ferrocarril y los más recientes talleres de las grandes empresas industriales norteamericanas, pueden compararse con la obra del antiguo Egipto por su contundente fuerza monumental". En este sentido, hay que recordar que la comparación entre ambas culturas también estuvo presente en la percepción histórica de su compatriota Wilhelm Worringer.

${ }^{9}$ Le Corbusier, Saugnier -pseudónimo de Amédée Ozenfant-, "Trois rappels á MM. les architectes", en L'Esprit Nouveau, 1, París, octubre de 1920, pp. 90-96.

${ }^{10}$ Antonio Sant'Elia, Filippo T. Marinetti, "L'Architettura futurista. Manifiesto", 1914, tr. al castellano como "La arquitectura futurista. Manifiesto", en Pere Hereu, Josep M. Montaner, Jordi Oliveras (eds.), Textos de arquitectura de la modernidad, Nerea, Madrid, 1994, pp. 164-167.

11 Jacobus J. Pieter Oud, "Het monumentale stadsbeeld", en De Stijl, vol. 1, 1, octubre de 1917, pp. 10-11.

12 Jacobus J. Pieter Oud, "Kunst en machine", en De Stijl, vol. 1, 3, enero de 1918, pp. 25-27.

13 Ibidem, p. 25. Tr. propia: "... monumentalidad significa: la relación organizada y controlada de lo subjetivo a lo objetivo...".

${ }^{14}$ Theo van Doesburg, "Aanteekeningen over monumentale kunst", en De Stijl, vol. 2, 1, noviembre de 1918 , pp. 10-12.

${ }^{15}$ Véanse Henry-Russell Hitchcock, "Modern architecture I: the traditionalists and the new tradition", en Architectural Record, 63, F.W. Dodge, Nueva York, abril de 1928, pp. 337-349; y Modern architecture: romanticism and reintegration, Payson \& Clarke, Nueva York, 1929.

${ }^{16}$ Criterio imperante tras los análisis más recientes de su ideario; véase lo escrito en Françoise Choay, Alegoría del patrimonio, Gustavo Gili, Barcelona, 2007, p. 114 [1992], que se contrapone a Laura Martínez de Guereñu, "Un atlas de paisajes", en Arquitectura Viva, 155, Madrid, 2013, pp. 54-56. Los mencionados bocetos corresponden, respectivamente, a Le Corbusier, Hacia una ar- quitectura, Apóstrofe, Barcelona, 1998, p. 128 [1923]; y "El plan 'Voisin' de París", Precisiones respecto a un estado actual de la arquitectura y el urbanismo, Apóstrofe, Barcelona, 1999, pp. 199 y 201 [1929] -conferencia pronunciada en Buenos Aires.

${ }^{17}$ Véase, Le Corbusier, "En defensa de la arquitectura", El Espíritu Nuevo en arquitectura. En defensa de la arquitectura, COAATM, Murcia, 2003, pp. 43-68.

${ }^{18} \mathrm{~A}$ modo de análisis retrospectivo, véase Giancarlo de Carlo, "The situation of modern movement", en Oscar Newman (ed.), CIAM '59 in Otterlo, Universe Books Inc., Stuttgart, 1961, pp. 80-91.

${ }^{19}$ Fritz Neumeyer, Mies van der Rohe. La palabra sin artificio; reflexiones sobre arquitectura 1922/1968, El Croquis, Madrid, 2000, p. 480 -como parte del "Discurso de ingreso como Director del Departamento de Arquitectura del Armour Institute of Technology (AIT)" impartido por el arquitecto alemán en 1938.

${ }^{20}$ Henry-Russell Hitchcock, Philip Johnson, The International Style. Architecture since 1922, W.W. Norton, Nueva York, 1932, p. 19. Tr. propia: "En la última década ha creado suficientes monumentos de renombre para demostrar su validez y vitalidad. Puede ser perfectamente comparado en relevancia con los estilos del pasado".

${ }^{21}$ Véase Franco Borsi, L'ordine monumentale in Europa (1929-39), Edizioni di Comunità, Milán, 1986.

${ }^{22}$ Walter Curt Behrendt, "Disqualification for the monumental", Modern building: its nature, problems and forms, Harcourt Brace, Nueva York; Martin Hopkinson, Londres, 1937, pp. 179-182.

${ }^{23}$ Ibidem, 182. Tr. propia: "Mientras que una sociedad aristocrática se complace en erigir toda clase de monumentos, utilizándolos como símbolos para inculcar a la gente el carácter estático de la construcción social, en una sociedad democrática cuya estructura, basada en el concepto de orden orgánico, es de carácter dinámico, no tiene ninguna utilidad $y$, por tanto, no existe deseo de monumento". 
${ }^{24}$ Lewis Mumford, The culture of cities, Harcourt, Brace \& Co, Nueva York, 1938. Su inclusión se hizo como un doble apartado: la primera parte fue recogida con el título original del anterior texto, pp. 433-439; mientras que la segunda quedó encabezada por "Flexibility and renewal", pp. 440-445 -ambas dentro del capítulo denominado "Social basis of the new urban order".

${ }^{25}$ Lewis Mumford, "The death of the monument", en J. Leslie Martin, Ben Nicholson, Naum Gabo (eds.), Circle: international survey of construction art, Faber \& Faber, Londres, 1937, p. 264. Tr. propia: "La noción de monumento moderno es contradictoria en sí misma: si es un monumento, no puede ser moderno; y si es moderno, no puede ser un monumento".

${ }^{26}$ Ibidem, p. 269. Tr. propia: "La reducción de nuestros monumentos mecánicos, entonces, no es menos imperiosa que la reducción de nuestros monumentos simbólicos".

${ }^{27}$ Sigfried Giedion, "Nine points on monumentality", Architecture, you and me. The diary of a development, Harvard University Press, Cambridge (MA), 1958, pp. 48-51.

${ }^{28}$ Véase Frank Lloyd Wright, When democracy builds, University of Chicago Press, Chicago, 1945, pp. 4-5.

${ }^{29} \mathrm{El}$ cual es considerado como texto complementario del anteriormente citado libro de Giedion -ambos editados por Harvard University Press.

${ }^{30}$ Véase Sigfried Giedion, op. cit., 1963, pp. 30-32. Para una más amplia contextualización, se puede consultar Joan Ockman, "Los años de la guerra: Nueva York, Nueva Monumentalidad / The war years in America: New York, New Monumentality", en Xavier Costa, Guido Hartray (eds.), Sert. Arquitecto en Nueva York, catálogo de exposición, Actar y Museu d'Art Contemporani de Barcelona, Barcelona, 1997, pp. 22-47.

${ }^{31}$ Cuya redacción se ultimó mediante correspondencia, como demuestra la carta de Giedion a Sert con fecha 23 de mayo de 1943 (Archivo Sigfried Giedion, ref. 43-K-1943-5-23(G), ETH Zúrich).

${ }^{32}$ Véase Kenneth Frampton, Historia crítica de la arquitectura moderna,
Gustavo Gili, Barcelona, 1987, p. 225 [1980].

${ }^{33}$ Publicado también de modo tardío, como apartado precedente a los Nine points, en Sigfried Giedion, op. cit., 1958, pp. 40-47.

${ }^{34}$ Véase Le Corbusier, "L'Espace indicible", en L'Architecture d'Aujourd'hui, número especial sobre Arte, abril de 1946, pp. 9-17.

${ }^{35}$ Sigfried Giedion, "The need for a new monumentality", en Paul Zucker (ed.), New architecture and city planning, Philosophical Library, Nueva York, 1944, pp. 549-568.

${ }^{36}$ Louis I. Kahn, "Monumentality", en ibidem, pp. 77-88.

${ }^{37}$ Expresión adoptada como título de Sigfried Giedion, The eternal present. A contribution on constancy and change, vol. 1: The beginnings of art $y$ vol. 2: The beginnings of architecture, Bollingen Foundation, Nueva York, 1962 y 1964.

38 Véase George Mosse, "Two world wars and myth of the war experience", en Journal of Contemporary History, vol. 21, 4, octubre de 1986, pp. 491-513, donde el historiador alemán justifica tal circunstancia, entre otras razones, porque dejó de existir el combate físico directo (como signo de coraje) y la distinción entre objetivos militares y civiles; lo que se acompañó de una cobertura mediática con imágenes funestas y un colofón tan execrable como la bomba atómica.

39 Para ampliar información sobre esta materia, se puede consultar Charles D. Maginnis (expresidente del AIA), "Living memorials: the war memorial", y Archibald MacLeish (poeta y bibliotecario del Congreso), "Living memorials: memorials are for remembrance", en The Architectural Forum, vol. 81, 3, septiembre de 1944, pp. 106-110 y 111-112 respectivamente; The American Commission for Living War Memorials, con The National Committee on Physical Fitness of the Federal Security Agency, Memorials that live. A brochure of suggestions concerning the use of recreational facilities as war memorials, The American Commission for Living War Memorials, Columbus (OH), 1944; Andrew M. Shanken, "Planning memory: living memorials in the United
States during World War II", en The Art Bulletin, vol. 84, 1, marzo de 2002, pp. 130-147; y Mariano Molina Iniesta, La idea de monumentalidad en la segunda posguerra: debates y propuestas, tesis doctoral, Universidad Politécnica de Madrid, 2015 [disponible en http:// oa.upm.es/39919].

${ }^{40}$ Véase Philip Johnson, "War memorials. What aesthetic price glory?", en Art News, vol. 44, 2, septiembre de 1945, pp. 8-10, 24-25.

${ }^{41}$ Gregor Paulsson, Henry-Russell Hitchcock, William Holford, Sigfried Giedion, Walter Gropius, Lucio Costa, Alfred Roth, "In search of a new monumentality", en The Architectural Review, vol. 104, 624, septiembre de 1948, pp. 117-128.

42 John Ruskin, Lectures on architecture and painting, John Wiley, Nueva York, 1854, II, p. 79. Tr. propia: "Considera [...] si deberíamos no tener la costumbre de buscar el honor a partir de nuestros descendientes en vez de nuestros antepasados; pensando más en ser recordados noblemente que en haber nacido noblemente".

${ }^{43}$ Formando parte del escrito "Defends discussion", p. 10. Tr. propia: "entre las contribuciones más significativas a la crítica arquitectónica reciente".

${ }^{44}$ Véanse Progressive Architecture, vol. 29, 12, diciembre de 1948, pp. 49, 120, 122 y 138; y Progressive Architecture, vol. 30, 1, enero de 1949, pp. 8, 10 y 12; Progressive Architecture, vol. 30, 2, febrero de 1949, pp. 8, 10 y 12.

${ }^{45}$ Lewis Mumford, "Monumentalism, symbolism and style", en The Architectural Review, vol. 105, 628, abril de 1949, p. 179. Tr. propia: "En esencia, el monumento es una declaración de amor y admiración ligada a los más altos propósitos que los hombres tienen en común [...]. La mayoría de las épocas, para que el monumento fuera posible, encendieron (en términos de Ruskin) la lámpara del sacrificio, dando al templo o los edificios públicos, no un exceso, sino su propia sangre vital...".

${ }^{46}$ Tanto ésta como la anterior cita forman parte de Christian NorbergSchulz, "La nueva monumentalidad", Los principios de la arquitectura moderna, Reverté, Barcelona, 2008, p. 223 [2000]. 
N $\quad 47$ José María Sostres, "La arquitec-

(1) tura monumental", en Revista Nacional

을 de Arquitectura, 113, Dirección Gene-

ral de Arquitectura, Madrid, mayo de

닌 1951, pp. 24-27.

음
$\frac{0}{0}$
0
0
을
$\overline{\bar{\varepsilon}}$
${ }^{48}$ Louis H. Sullivan, "El ornamento en arquitectura", Charlas con un arquitecto (kindergarten chats $y$ otros escritos), Infinito, Buenos Aires, 1959, p. 182 [1892].
${ }^{49}$ José María Sostres, op. cit., p. 24. 


\section{REFERENCIAS}

Banham, Reyner. 1989. La Atlántida de hormigón. Madrid: Nerea.

Behrendt, Walter Curt. 1937. "Disqualification for the monumental." In Modern building: its nature, problems and forms, 179-82. New York: Harcourt Brace; Londres: Martin Hopkinson.

Borsi, Franco. 1986. L'ordine monumentale in Europa (1929-39). Milan: Edizioni di Comunità.

Carlo, Giancarlo de. 1961. "The situation of modern movement." In CIAM '59 in Otterlo, edited by Oscar Newman, 80-91. Stuttgart: Universe Books Inc.

Choay, Françoise. 2007. Alegoría del patrimonio. Barcelona: Gustavo Gili.

Doesburg, Theo van. 1918. "Aanteekeningen over monumentale kunst." De Stijl 2, no. 1 (November): 10-2.

Frampton, Kenneth. 1987. Historia crítica de la arquitectura moderna. Barcelona: Gustavo Gili.

Giedion, Sigfried. 1944. "The need for a new monumentality." In New architecture and city planning, edited by Paul Zucker, 549-68. New York: Philosophical Library.

Giedion, Sigfried. 1958. "Nine points on monumentality." In Architecture, you and me. The diary of a development, 48-51. Cambridge, MA: Harvard University Press.

Giedion, Sigfried. 1962-64. The eternal present. A contribution on constancy and change. 2 vols. New York: Bollingen Foundation.

Giedion, Sigfried. 1963. Arquitectura y Comunidad. Buenos Aires: Nueva Visión.

Gropius, Walter. 1913. "Die entwicklung moderner industriebaukunst." In Jahrbuch des Deutschen Werkbundes. Die kunst in industrie und handel, edited by Deutschen Werkbundes, 17-22. Jena: Diederichs.

Gropius, Walter. 1983. "Monumentale kunst und industriebau." In Walter Gropius, industriearchitekt, edited by Karin Wilhelm, 116-20. Braunschweig and Wiesbaden: Vieweg.
Hitchcock, Henry-Russell. 1928. "Modern architecture I: the traditionalists and the new tradition." Architectural Record 63 (April): 337-49.

Hitchcock, Henry-Russell. 1929. Modern architecture: romanticism and reintegration. New York: Payson \& Clarke.

Hitchcock, Henry-Russell, and Philip Johnson. 1932. The International Style. Architecture since 1922. New York: W.W. Norton.

Johnson, Philip. 1945. "War memorials. What aesthetic price glory?" Art News 44, no. 2, (September): 8-10, 24-5.

Kahn, Louis I. 1944. "Monumentality." In New architecture and city planning, edited by Paul Zucker, 77-88. New York: Philosophical Library.

Le Corbusier, and Saugnier. 1920. "Trois rappels á MM. les architectes." L'Esprit Nouveau 1 (October): 90-6.

Le Corbusier. 1946. "L'Espace indicible." L'Architecture d'Aujourd'hui, special no. about Art (April): 9-17.

Le Corbusier. 1998. Hacia una arquitectura. Barcelona: Apóstrofe.

Le Corbusier. 1999. "El plan 'Voisin' de París." In Precisiones respecto a un estado actual de la arquitectura y el urbanismo, 193-237. Barcelona: Apóstrofe.

Le Corbusier. 2003. "En defensa de la arquitectura." In El Espíritu Nuevo en arquitectura. En defensa de la arquitectura, 43-68. Murcia: COAATM.

Loos, Adolf. 2004. "Arquitectura." In Adolf Loos. Escritos I/ 1910/1932, edited by Adolf Opel, and Josep Quetglas, 23-35. Madrid: El Croquis.

MacLeish, Archibald. 1944. "Living memorials: memorials are for remembrance." The Architectural Forum 81, no. 3 (September): 111-2.

Maginnis, Charles D. 1944. "Living memorials: the war memorial." The Architectural Forum 81, no. 3 (September): 106-110.

Martínez de Guereñu, Laura. 2013. "Un atlas de paisajes." Arquitectura Viva 155: 54-6.

Molina Iniesta, Mariano. 2015. La idea de monumentalidad en la segunda posguerra: debates 
y propuestas. PhD diss., Universidad Politécnica de Madrid.

Mosse, George L. 1986. "Two world wars and myth of the war experience." Journal of Contemporary History 21, no. 4 (October): 491-513. https://doi. org/10.1177/002200948602100401

Mumford, Lewis. 1937. "The death of the monument." In Circle: international survey of construction art, edited by J. Leslie Martin, Ben Nicholson, and Naum Gabo, 263-70. London: Faber \& Faber.

Mumford, Lewis. 1938. The culture of cities. New York: Harcourt, Brace \& Co.

Mumford, Lewis. 1949. "Monumentalism, symbolism and style." The Architectural Review 105, no. 628 (April): 173-80.

Neumeyer, Fritz. 2000. Mies van der Rohe. La palabra sin artificio; reflexiones sobre arquitectura 1922/1968. Madrid: El Croquis.

Norberg-Schulz, Christian. 2008. "La nueva monumentalidad." Los principios de la arquitectura moderna, 207-28. Barcelona: Reverté.

Ockman, Joan. 1997. “Los años de la guerra: Nueva York, Nueva Monumentalidad / The war years in America: New York, New Monumentality." In Sert. Arquitecto en Nueva York, edited by Xavier Costa, and Guido Hartray, 22-47. Barcelona: Actar, and Museu d'Art Contemporani de Barcelona.

Oud, Jacobus J. Pieter. 1917. "Het monumentale stadsbeeld." De Stijl 1, no. 1 (October): 10-1.

Oud, Jacobus J. Pieter. 1918. "Kunst en machine." De Stijl 1, no. 3 (January): 25-7.

Paulsson, Gregor, Henry-Russell Hitchcock, WiIliam Holford, Sigfried Giedion, Walter Gropius, Lucio Costa and Alfred Roth. 1948. "In search of a new monumentality." The Architectural Review 104, no. 624 (September): 117-28.

Progressive Architecture 29, no. 12. (December). 1948.
Progressive Architecture 30, no. 1. (January). 1949.

Progressive Architecture 30, no. 2 (February). 1949.

Riegl, Aloïs. 1903. Der moderne denkmalkultus. Sein wesen und seine entstehung. Viena, and Leipzig: Braumüller.

Ruskin, John. 1854. Lectures on architecture and painting. New York: John Wiley.

Sant'Elia, Antonio, and Filippo T. Marinetti. 1994. "La arquitectura futurista. Manifiesto." In Textos de arquitectura de la modernidad, edited by Pere Hereu, Josep M. Montaner, and Jordi Oliveras, 164-7. Madrid: Nerea.

Sert, Josep Lluís, Fernand Léger, and Sigfried Giedion. 2015. "Nueve puntos sobre monumentalidad." URBS. Revista de Estudios Urbanos y Ciencias Sociales 5 (2): 197-206. Translated by José María Coco Ferraris and comment of Emilio Cachorro Fernández. http://www2.ual. es/urbs/index.php/urbs/article/view/cachorro.

Shanken, Andrew M. 2002. "Planning memory: living memorials in the United States during World War II." Art Bulletin 84, no. 1 (March): 130-47. https://doi.org/10.2307/3177256

Sostres, José María. 1951. "La arquitectura monumental." Revista Nacional de Arquitectura 113 (May): 24-7.

Sullivan, Louis H. 1959. "El ornamento en arquitectura." In Charlas con un arquitecto (kindergarten chats y otros escritos), 182-5. Buenos Aires: Infinito.

The American Commission for Living War Memorials, with The National Committee on Physical Fitness of the Federal Security Agency. 1944. Memorials that live. A brochure of suggestions concerning the use of recreational facilities as war memorials. Columbus, $\mathrm{OH}$ : The American Commission for Living War Memorials.

Wright, Frank Lloyd. 1945. When democracy builds. Chicago: University of Chicago Press. 